Supporting Information

\title{
Reverse Thermal Gelling PEG-PTMC Diblock Copolymer
}

\section{Aqueous Solution}

Figure S1. a) ${ }^{1} \mathrm{H}-\mathrm{NMR}$ spectra in $\mathrm{CDCl}_{3}$, b) FTIR spectra of the PEG-PTMC (550-

2750) diblock copolymer. c) Gel permeation chromatograms of PEG (550) and PEG-

PTMC (550-2750) diblock copolymer.

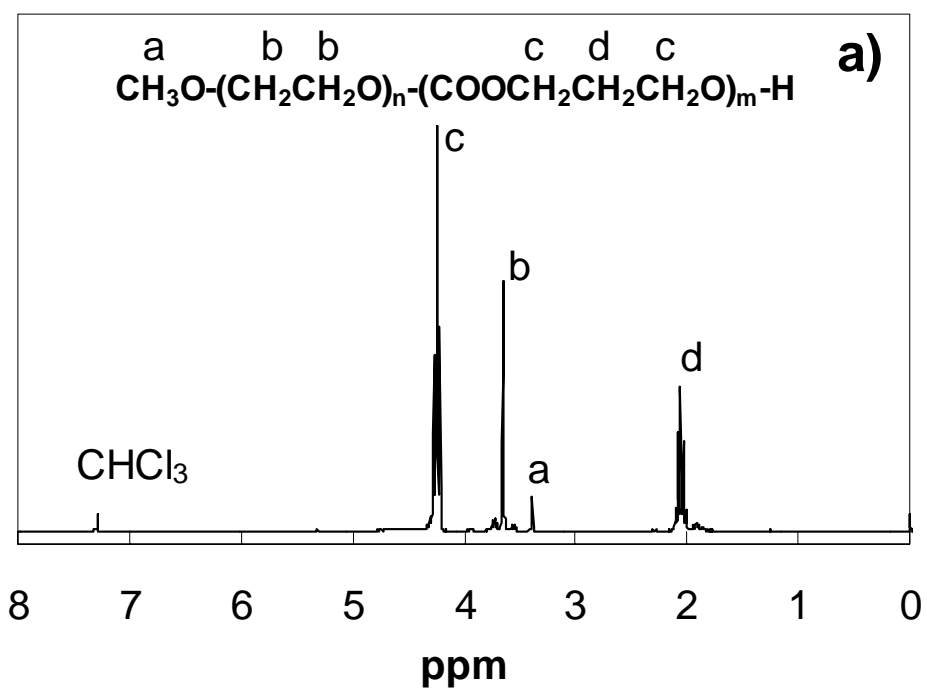



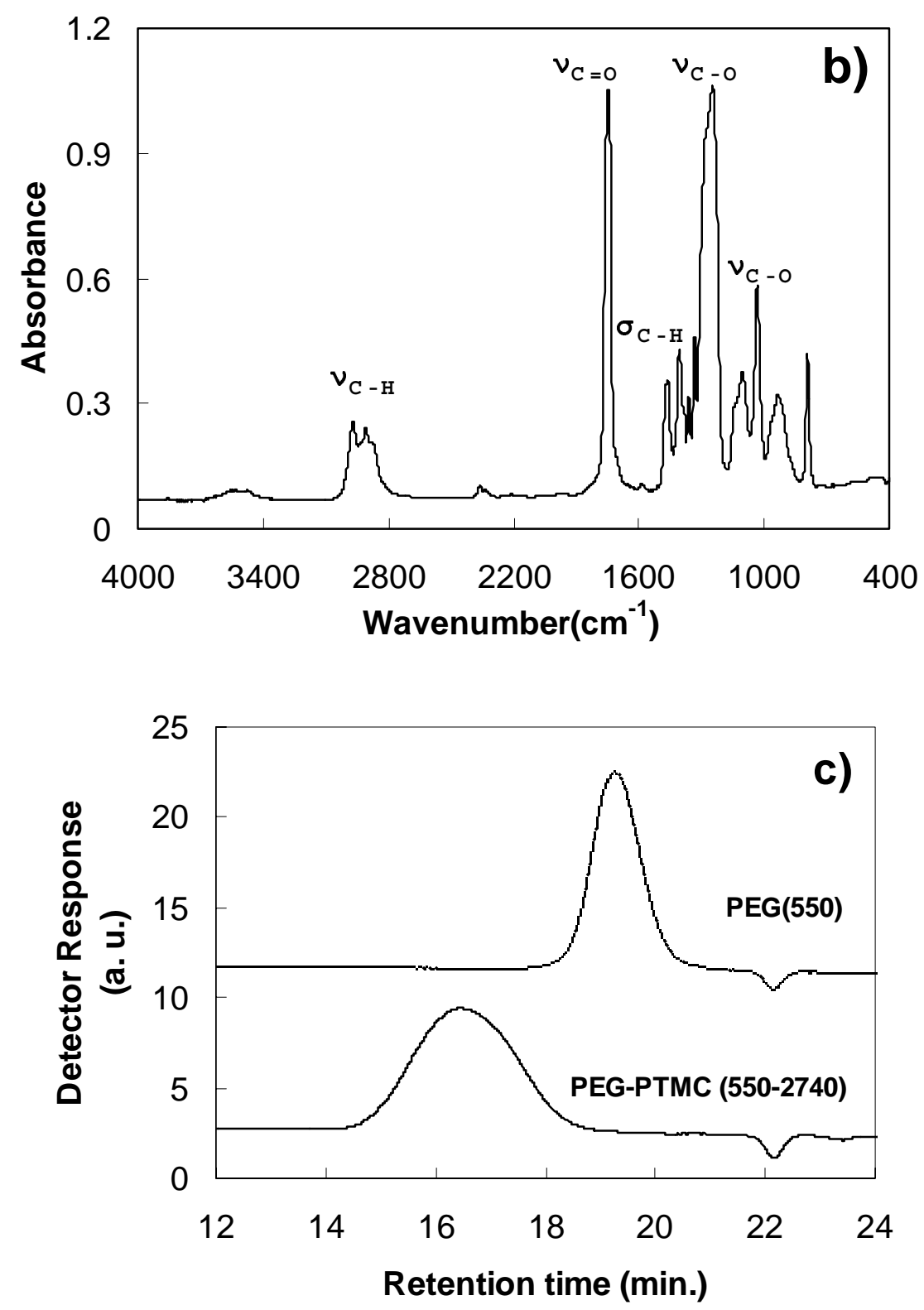
Figure S2. In-situ gel formation and degradation of the PEG-PTMC. The photos were taken 1, 3, 10, and 20 days after the subcutaneous injection of the PEG-PTMC aqueous solution (30 wt. $\% ; 0.5 \mathrm{~mL} / \mathrm{rat}$ ) into the rats.
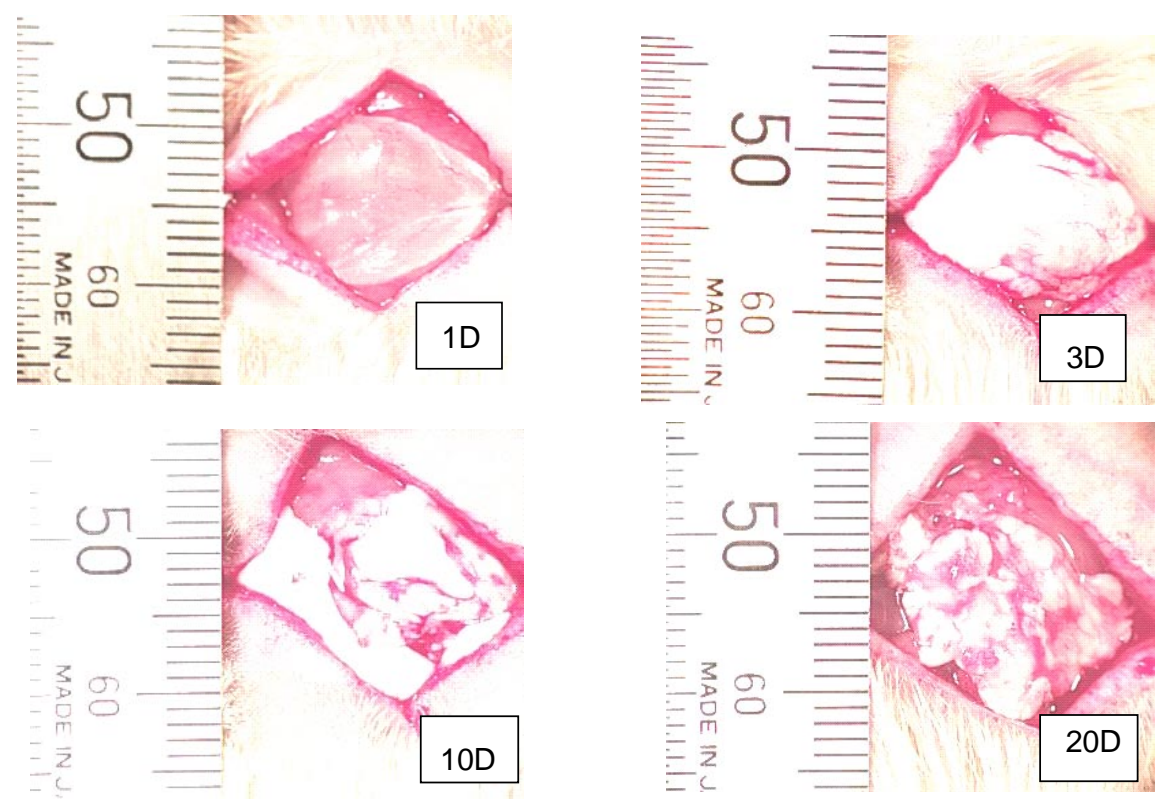
Figure S3. GPC traces of the PEG-PTMC (550-2750) during storage at room temperature $\left(20^{\circ} \mathrm{C}\right)$ in phosphate buffer saline $(30 \mathrm{wt} . \%$; $0.5 \mathrm{~mL})$. The GPC were investigated 30, 60, 90 days after storing the PEG-PTMC aqueous solution at $20^{\circ} \mathrm{C}$.

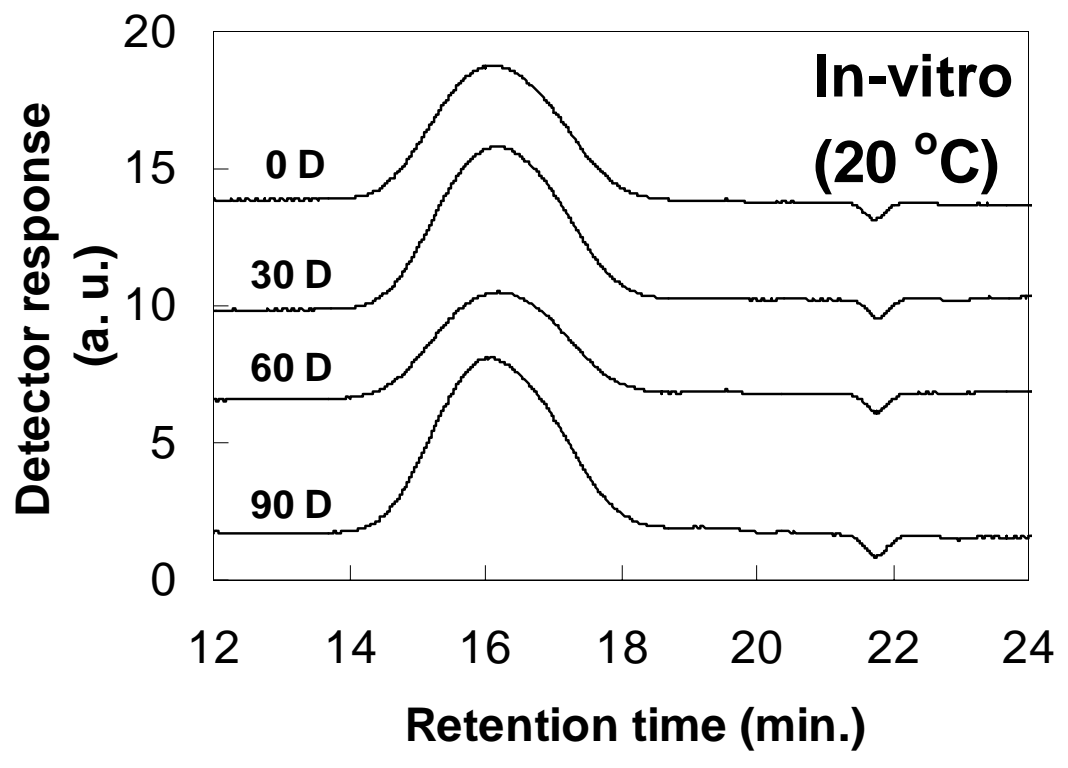

